Document downloaded from:

http://hdl.handle.net/10251/155118

This paper must be cited as:

Esteso, A.; Mula, J.; Campuzano-Bolarín, F.; Alemany Díaz, MDM.; Ortiz Bas, A. (2019). Simulation to reallocate supply to committed orders under shortage. International Journal of Production Research. 57(5):1552-1570. https://doi.org/10.1080/00207543.2018.1493239

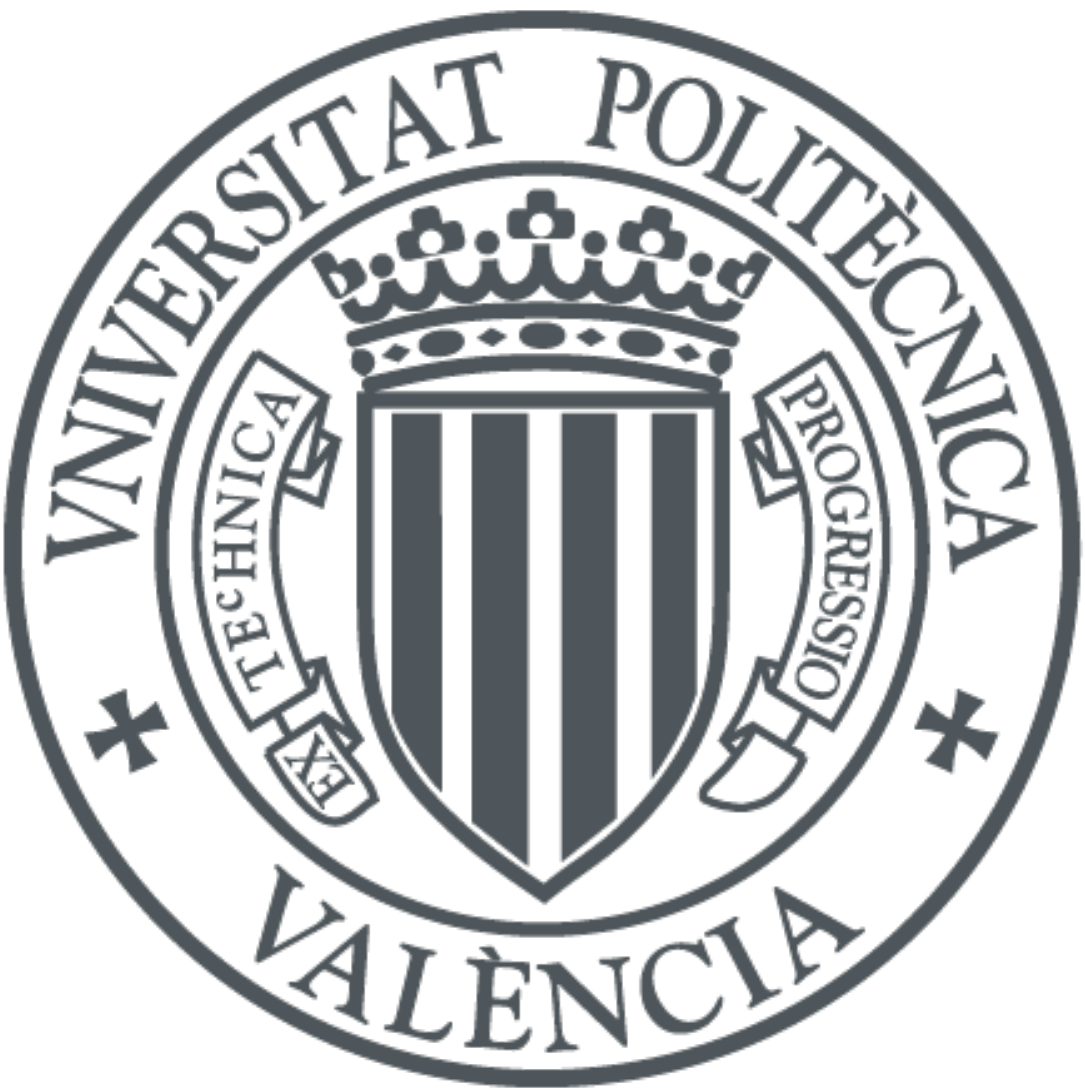

The final publication is available at

https://doi.org/10.1080/00207543.2018.1493239

Copyright Taylor \& Francis

Additional Information 


\title{
Simulation to reallocate supply to committed orders under shortage
}

\author{
${ }^{1}$ Ana Esteso, ${ }^{2}$ Josefa Mula, ${ }^{3}$ Francisco Campuzano-Bolarín, ${ }^{1}$ MME Alemany, ${ }^{1}$ Angel Ortiz \\ ${ }^{1}$ Research Centre of Production Management and Engineering (CIGIP), Universitat \\ Politècnica de València, Camí de Vera s/n, 46022 Valencia, Spain, \\ (email: aneslva@doctor.upv.es, mareva@omp.upv.es, aortiz@omp.upv.es) \\ ${ }^{2}$ Universitat Politècnica de València, Research Centre on Production Management and \\ Engineering (CIGIP), Plaza Ferrándiz y Carbonell, 2, 03801, Alcoy, Alicante, Spain, \\ (email: fmula@omp.upv.es) \\ ${ }^{3}$ Department of Business Economics, Universidad Politécnica de Cartagena, \\ Cartagena, Spain, \\ (email: francisco.campuzano@upct.es)
}

\begin{abstract}
This article aims to deal with the problem of reallocating supply, in both its real and planned contexts, to orders that result from the order promising process under shortage. To this end, we propose a system dynamics-based simulation model to facilitate modelling for order managers, and to provide a graphic support tool to understand the process and to make decisions. The basis of the simulation model's structure is a mixed integer linear programming approach which intends to maximise profits by considering the possibility of making partial and delayed deliveries. To illustrate, we consider a real world problem from the ceramic sector that contemplates 35 orders. We obtained a solution by a mathematical programming model and a simulation model. The results show the simulation model's capacity to obtain nearoptimum results, and to provide a simulated history of the system.
\end{abstract}

Keywords: Available-to-promise, lack of homogeneity, shortage, simulation, system dynamics, ceramic sector.

\section{Introduction}

According to Olhager (2003), the order penetration point defines the stage in the manufacturing value chain, where a particular product is linked to a specific customer order through different product delivery strategies such as make-to-stock, assemble-toorder, make-to-order and engineer-to-order. In this paper, we consider a manufacturing environment of make-to-stock. During the order promising (OP) process, companies normally make commitments with customers about the quantities and due dates of their orders. These commitments focus usually in make-to-stock companies on the availableto-promise (ATP) quantities of finished goods calculated as the current stock and planned production defined in the master production schedule (MPS), minus any past orders promised.

However, from the time we commit an order until we must serve it, unexpected events can occur that may lead to shortage of products. There are several causes of these unexpected events: i) arrival of more priority customer orders that require already reserved products, ii) delays in raw materials or components; iii) machine breakdowns; iv) absenteeism of workers, among others. Some of these events might lead to 
discrepancies between planned and real production quantities and, in turn, can lead to a shortage situation.

Consequently, the previous allocation of products to orders may become suboptimum, or even unfeasible. In this case, the company might not be able to meet previously agreed conditions with customers. This situation becomes relevant because it could very negatively impact not only the company's profits, but also customer satisfaction. Furthermore, if this situation occurs often, it could seriously harm customer loyalty and the company's future sustainability. In this context, the shortage planning process intends to find a solution when stock (component or finished products) is unavailable. Solutions include decisions on supply alternatives (outsourcing, substitute products), late supply, partial shipments, etc. (Framinan and Leisten, 2010). Indeed, the solutions to these shortage situations seriously impact the reliability of the OP processing. Therefore, the recognised relevance of the OP processing in the literature to better deal with demand requirements with high standards of service level and customer satisfaction (Alemany et al., 2015a; Grillo et al., 2016) supports the importance of shortage planning (SP).

The frequency of unexpected events increases when companies are characterised by lack of homogeneity in the product (LHP), which renders having to execute the SP process more frequently. LHP is an important issue because it appears in several industries like ceramics, textile, wood, marble, horticulture, tanned hides and leather goods, among others (Grillo et al. 2017). LHP implies the company producing to provide units of the same product with different relevant characteristics for customers. Indeed, customers require homogeneity among the units of a particular product that comprises their orders (e.g., in the horticulture sector, fruit should present the same quality and calibre; in the ceramic sector, tiles should be of the same quality, tone (colour) and calibre (thickness)).

In the ceramic sector, the main causes of LHP are the origin and composition of raw materials, and changes in environmental conditions during production (e.g. temperature, humidity). Thus, a particular production lot leads to units of product that may differ in terms of: i) quality, ii) tone (colour), and iii) calibre (thickness). This aspect would not become a management problem if customers were not sensitive to such differences. However, customers require homogeneity among the ordered units of a particular product for aesthetic and functional reasons. Therefore, after manufacturing a production lot, it is necessary to classify it into different sublots comprised of product units that are homogeneous to one another for all the above-cited characteristics (Davoli et al. 2010).

Companies with LHP are obliged to classify production lots into different homogeneous sublots to comply with customers' homogeneity requirements. Moreover, the quantity of products that comprises each homogeneous sublot is not known for certain until the lots are manufactured and classified after manufacturing and classifying the production lot. For this reason, it is necessary to estimate the distribution of homogeneous sublots in the MPS during the OP processing. However, given the uncertainty in this distribution, discrepancies usually appear between the planned and real homogeneous sublots obtained after production. These discrepancies can mean that it is not possible to serve or fulfil some committed orders under previously agreed conditions because there are not enough homogeneous quantities to fulfil all the orders.

Evidently, we can deduce that the shortage situation very often occurs in companies with LHP. So, developing a method to solve this problem is crucial for such companies. One 
possible SP solution could involve reallocating available (in stock and planned) quantities to previously committed orders to serve those orders which, in the new circumstances, optimise the objective set by the company (Alarcón et al. 2011).

Finding not only an optimal solution for the reallocation problem in the ceramic sector, but also a feasible one, is an extremely complicated task. The main causes of this complexity are: i) numerous references to be managed (classification of lots into homogeneous sublots entails increasing the number of product references to be handled); ii) some orders include more than one product; iii) the need to comply with customer homogeneity requirements; iv) usually the very short time available to reallocate. Thus, it is necessary to develop new tools to help decision making during the process of reallocating homogeneous sublots to committed orders under shortage.

One of the tools most widely used to tackle this problem is mathematical programming. Table 1 shows a literature review of the models used for the allocation/reallocation of available quantities to orders in the ceramic sector, and a comparison made with the characteristics of the model herein proposed. For each existing model, we analysed: i) the tackled problem, namely OP processing, or SP; ii) the modelling context, namely deterministic, or uncertain; iii) available quantities, namely real stock, planned production for SP or ATP for OP processing; iv) delivery flexibility, namely delays allowed, or partial deliveries of order lines; v) the modelling approach, namely mathematical programming or system dynamics.

Table 1. Literature review of the allocation/reallocation models

\begin{tabular}{|c|c|c|c|c|c|c|c|c|c|c|c|}
\hline \multirow[t]{2}{*}{ References } & \multicolumn{2}{|c|}{$\begin{array}{l}\text { Problem } \\
\text { tackled }\end{array}$} & \multicolumn{2}{|c|}{$\begin{array}{l}\text { Modelling } \\
\text { context }\end{array}$} & \multicolumn{3}{|c|}{ Product origin } & \multicolumn{2}{|c|}{$\begin{array}{l}\text { Delivery } \\
\text { flexibility }\end{array}$} & \multicolumn{2}{|c|}{$\begin{array}{l}\text { Modelling } \\
\text { approach }\end{array}$} \\
\hline & $\mathrm{OP}$ & SP & $\mathrm{D}$ & $\mathrm{U}$ & $\mathrm{RS}$ & $\mathrm{PP}$ & ATP & DA & POL & MP & SD \\
\hline Alemany et al. (2013a) & & $\mathrm{X}$ & $\mathrm{X}$ & & $\mathrm{X}$ & & & & & $\mathrm{X}$ & \\
\hline Alemany et al. (2013b) & $\mathrm{X}$ & & $\mathrm{X}$ & & & & $\mathrm{X}$ & & & $\mathrm{X}$ & \\
\hline Boza et al. (2014) & & $\mathrm{X}$ & $X$ & & $X$ & & & & & $X$ & \\
\hline Alemany et al. (2015b) & & $\mathrm{X}$ & & $\mathrm{X}$ & $\mathrm{X}$ & $\mathrm{X}$ & & $\mathrm{X}$ & & $\mathrm{X}$ & \\
\hline This paper & & $\mathrm{X}$ & $X$ & & $\mathrm{X}$ & $\mathrm{X}$ & & $\mathrm{X}$ & $\mathrm{X}$ & $\mathrm{X}$ & $\mathrm{X}$ \\
\hline
\end{tabular}

Alemany et al. (2013a) formulated a mixed-integer linear programming (MILP) model for solving the SP problem in LHP contexts. The model reallocates only existing stocks of multiple products to multiple-line orders, while ensuring homogeneity between the units of product that comprise each order line. The objectives of this model were to: i) maximise profits and ii) maximise the number of orders delivered with an earliest due date. It does not allow either delayed deliveries or partial deliveries of order lines. Subsequently, Boza et al. (2014) extended this model and used it as a basis for a decisionsupport system.

Alemany et al. (2013b) also proposed a MILP model, but to support the OP processing in LHP contexts that relates closely with SP. This model estimated the distribution of planned production lots in the MPS into homogeneous sublots for ATP computation purposes. Then the model decided on the acceptance/rejection of customer order proposals, and allocated the homogeneous ATP quantities of multiple products to the accepted multiple-line orders. It did not anticipate subtypes in sublots because customer 
orders only needed serving with homogeneous units despite subtypes. Apart from the traditional objective of maximising profits, these authors implemented the maximisation of exhausted ATPs when allocating homogeneous ATP to customer orders. This model allowed delays in deliveries, but not partial deliveries of order lines.

Finally, Alemany et al. (2015b) presented a fuzzy mixed integer programming model for solving the SP problem in LHP contexts. This model considered uncertainty in the distribution of planned production lots in homogeneous sublots. The model reallocated both real and planned homogeneous quantities of products to already committed order lines. It considered multiple products and customer orders comprised more than one order line. The objective of this model was to maximise the profit made. This model allowed delays in deliveries, but not partial deliveries of order lines.

Although the above mathematical programming models are most valuable, they can require long computation times to optimally solve them when the numbers of orders, products, subtypes and periods of time of the planning horizon are high. This can be especially relevant for the SP problem for two reasons. During SP, all the previously committed orders by the company should be taken into account. This aspect implies that the size of the problem becomes very large. At the same time, as the very limited time between the time of the real homogeneous quantities is known and the delivery of orders, methods are necessary to provide a solution to the SP problem in a short time.

The theoretical framework used for the modelling and analyses in this research work is system dynamics (Forrester, 1961; Sterman, 2000). In this paper, we propose a system dynamics approach, validated with an also novel MILP model, to overcome the abovecited drawbacks. To the best of our knowledge, no research proposes a simulation-based model to address the OP processing or SP problem. Our proposal also allows partial deliveries of order lines not previously addressed, which is the main novelty of the proposed MILP model. Besides the shorter computation times, simulation-based models can explain how process performance indicators react to changes in controllable factors or in the environment. Accordingly, managers can benefit from simulation models in several ways. They can contribute to: i) study the system changes in the model; ii) verify analytical solutions; iii) provide a view about key variables and how they interact; iv) experiment with new situations that involve risk or uncertainty; v) test new policies and decision rules (Campuzano and Mula, 2011; Campuzano et al. 2013). We refer readers to Tako and Robinson (2011) and to Jeo and Kim (2016) for extensive reviews of simulation models applied to logistics, supply chains, and production planning and control contexts.

For this reason, the present article aims to design a system dynamics-based simulation model to support the SP process in the ceramic sector. The proposed solution is to reallocate homogeneous quantities of product to committed orders in order to optimise the company objectives. To this end, this model considers not only the real homogeneous sublots of product in stock, but also the planned homogeneous sublots to be produced. It is important to highlight that each homogeneous sublot is unique, so that sublots from different production lots cannot be combined to serve an order. When reallocating supply to customer orders, partial deliveries and/or some delays become flexible. The working basis of this simulation model is a mathematical programming model. Thus, analytical models offer optimum solutions, whereas simulation models: i) reflect a suitable degree of realism and accuracy in describing the system; ii) are capable of robustly and 
efficiently providing scenarios or what-if and sensitivity analyses (Georgiadis and Michaloudis, 2012; Georgiadous and Politou, 2013; Mula et al. 2013). All this provides a better evaluation and understanding of the problem under study.

The rest of the paper includes: Section 2 describes the problem. Section 3 presents the MP model, taken as a basis for reallocating real homogeneous stocks and planned homogeneous sublots to committed orders. Section 4 shows the simulation model devised for planning shortages in the ceramic sector. Section 5 describes the model's application, its validation in the ceramic sector, and analyses the results. Finally, Section 6 offers the obtained conclusions and the future research lines identified while conducting this work.

\section{Description of the problem}

As previously mentioned, this paper aims to provide solutions to the SP problem by reallocating (real and planned) available homogeneous quantities to already committed orders in the ceramic sector. LHP characterises the ceramic sector, which means that a particular production lot leads to units of the same product having different attributes. In this sector, such attributes are: i) quality, ii) colour and iii) calibre. Uncontrollable causes can be the reason for these products' heterogeneity, which are mainly the composition of raw materials and/or changes in the environment during production. This means that the available homogeneous quantities obtained from the MPS are not known with certainty until after their manufacturing and classification. At the same time, customers require homogeneity in the above-mentioned attributes for the units of product that comprise each order line for aesthetic and assembly reasons.

During the OP processing, customer orders are not only committed with the homogeneous quantities of product available in warehouses, but also with the planned homogeneous quantities that derive from the MPS. Therefore, it is necessary to initially estimate the distribution of lots into homogeneous sublots. Once production finishes, we can know the real distribution with certainty. Discrepancies between the estimated and real distribution of lots into homogeneous sublots can cause a shortage situation. As a result, it is not possible to serve some previously committed orders on the due date because there would be not enough homogeneous product. The SP intends to reallocate homogeneous quantities to orders to maximise the customer service level for the company as efficiently as possible.

It is necessary to consider the homogeneity attributes of products when following the SP process in ceramic companies because of the need to serve customers not only with the agreed quantity and due date, but to also meet customers' homogeneity requirements.

We solve the SP process here by reallocating the real and planned products' homogeneous quantities to the previously committed orders that resulted from the OP processing. This paper examines a company that works according to the following assumptions:

- The orders committed during the OP processing can include one order line or more.

- For each order line, the customer specifies the required product and quantity to be served with homogeneous units.

- All the lines of the same customer order present the same due date, which coincides with the committed due date that results from the OP processing. 
- It is not possible to serve an order line through partial deliveries because it implies the need to deliver all the quantity that comprises an order line during the same period of time. Not serving an order line involves a penalisation by rejecting costs.

- The model allows partial deliveries of complete order lines. It assumes that customers pick up their orders at the company and are in charge of the associated costs. For this reason, the number of partial deliveries does not affect the company's profit.

- If it is not possible to serve all the orders on the committed due date after the reallocation process, it contemplates a maximum delay allowed for the delivery of each order. Therefore, it is necessary to compromise the final delivery date of each customer order line between the interval defined by an earliest and latest due date where:

- the earliest due date that a customer accepts a delivery is the committed due date provided by the OP processing.

- the latest due date that a customer accepts a delivery is the earliest due date, plus the maximum delays allowed for his/her order.

Figure 1 shows how the delivery terms are defined from the committed due date provided by the order promising process $(d d)$ and the maximum delay allowed for each order $(\max d)$. This figure also shows how homogeneous product allocated to a specific order is reserved until its committed due date. For example, if an order is going to be served with product that is available before the order's due date, it is necessary to reserve $(R)$ this product until the due date and hold it in inventory until delivery (e.g. Order 1 and 2 on Figure 1). In other cases, such as the represented in Order 3, the order will be served with product planned to be produced at the same or a posterior period to the committed due date. In these cases, the allocated product will not be reserved after production but directly sent to customer.

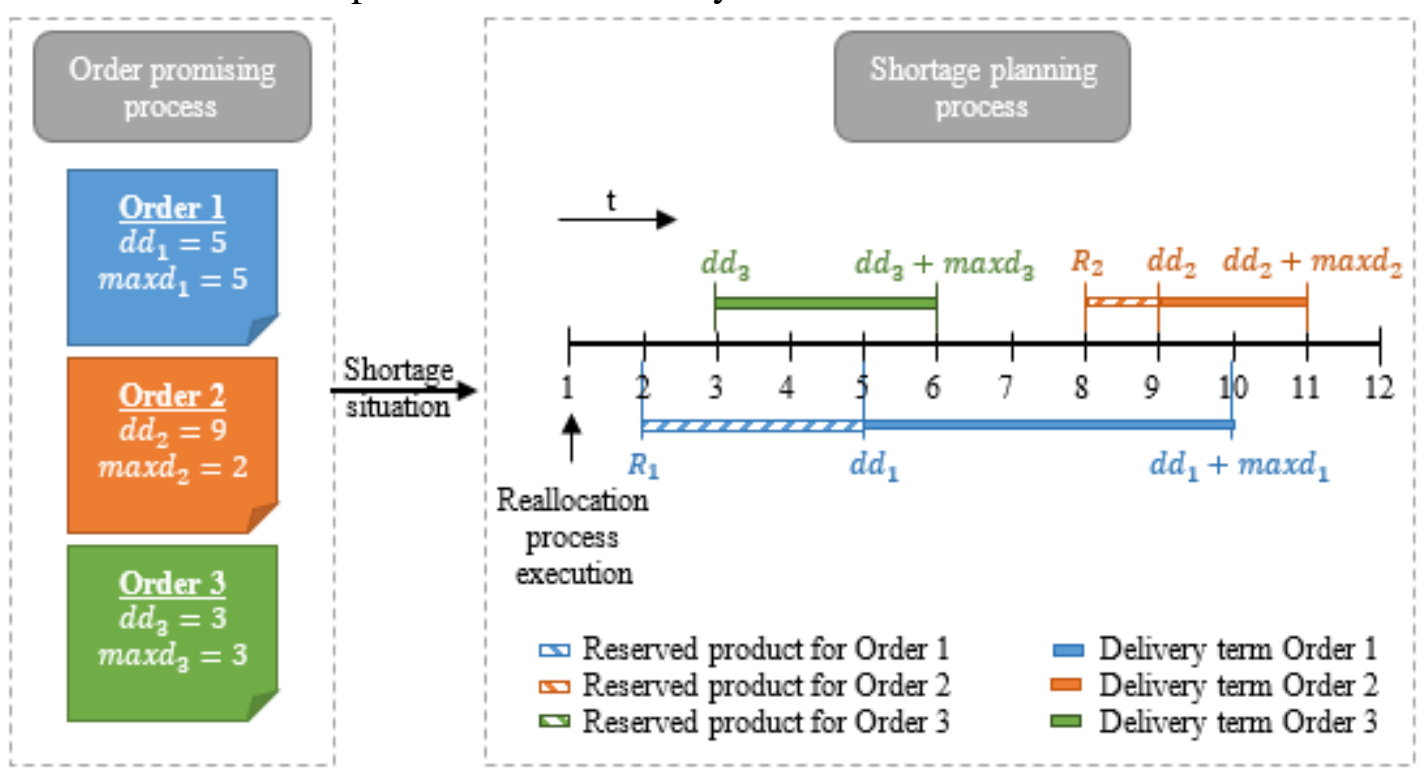

Figure 1. Delivery term definition

- To serve customer orders on time, prioritisation is possible by means of the maximum delays allowed: the shorter the maximum delays allowed for a customer order, the greater the priority of serving this order on the committed due date by the OP processing. 
- As the maximum delays allowed manages the priority of serving customers on time, it does not contemplate any penalty costs of late deliveries as regards the initial due date of the OP processing.

- The homogeneous quantities of product available in stock are known. The model estimates the distribution of a production lot into different homogeneous sublots by the so-called coefficients of homogeneity. These coefficients represent the fraction of a lot considered homogeneous (i.e. of the same subtype).

- The company's objective is to maximise the profits calculated as the difference between incomes from serving customer orders and the costs generated by rejecting and/or reserving products in advance to the committed due dates (holding costs).

- Economic data per product unit are known (profit, rejecting costs, and holding costs).

\section{MP model formulation}

By following these assumptions, we propose a MILP model for reallocating available homogeneous quantities to committed orders. Table 2 presents the notation employed in the model.

Table 2. Nomenclature for the MP model

\begin{tabular}{|c|c|}
\hline \multicolumn{2}{|l|}{ Indices } \\
\hline$O$ & Overall committed customer orders \\
\hline$k$ & Finished products required in the committed orders \\
\hline$S$ & Existing subtypes of all the finished products in the committed customer orders \\
\hline$t$ & Time periods \\
\hline \multicolumn{2}{|c|}{ Parameters } \\
\hline$D_{o k}$ & Quantity of product $k$ demanded in customer order $o$ \\
\hline$p_{k}$ & Per unit price of product $k$ \\
\hline$r c_{k}$ & Per unit reject cost of product $k$ \\
\hline$h c_{k}$ & Per unit inventory holding costs of product $k$ \\
\hline stock $_{k s}$ & Total available stock of subtype $s$ of product $k$ \\
\hline$m p s_{k t}$ & Planned quantity of product $k$ which becomes available during time period $t$ \\
\hline$n l_{o}$ & Number of order lines in customer order $o$ \\
\hline$d d_{o}$ & Committed due date of customer order $o$ \\
\hline $\operatorname{maxd}_{o}$ & Maximum delay allowed for customer order $o$ in relation to the committed due date \\
\hline$\beta_{k s}$ & Fraction of each lot of product $k$ of subtype $s$ \\
\hline \multicolumn{2}{|c|}{ Decision variables } \\
\hline$A 0_{k s}$ & Uncommitted available quantity of subtype $s$ of product $k$ after the reallocation process \\
\hline$A_{\text {kst }}$ & $\begin{array}{l}\text { Uncommitted available quantity of subtype } s \text { of product } k \text { derived from the } m p s_{k t} \text { after } \\
\text { the reallocation process }\end{array}$ \\
\hline$U 0_{\text {oks }}$ & $\begin{array}{l}\text { Identifies if the requested quantity of finished product } k \text { in customer order } o \text { is } \\
\text { completely served by uncommitted stock with subtype } s\end{array}$ \\
\hline$U_{\text {okst }}$ & $\begin{array}{l}\text { Identifies if the requested quantity of finished product } k \text { in customer order } o \text { is } \\
\text { completely served by uncommitted planned product in } m p s_{k t}\end{array}$ \\
\hline$Y K_{o k}$ & $\begin{array}{l}\text { Identifies if the order line of customer order } o \text { that corresponds to finished product } k \text { is } \\
\text { completely served }\end{array}$ \\
\hline$A D_{o k}$ & $\begin{array}{l}\text { Number of periods of time where the required quantity of product } k \text { in customer order } o \\
\text { is reserved until its delivery }\end{array}$ \\
\hline$L D K_{o k}$ & $\begin{array}{l}\text { Number of periods of time of delay in delivering product } k \text { in customer order } o \text { in } \\
\text { relation to the committed due date } d d_{o}\end{array}$ \\
\hline$D K_{o k t}$ & Identifies if finished product $k$ in customer order $o$ is served at period of time $t$ \\
\hline
\end{tabular}


The objective of the model, Equation (1), is to maximise profits, calculated as the difference between the incomes obtained when serving orders and the costs of rejecting orders and reserving quantities of product for future deliveries.

$$
\text { Max Profit }=\sum_{o} \sum_{k} D_{o k} *\left[p_{k} * Y K_{o k}-r c_{k} *\left(1-Y K_{o k}\right)-h c_{k} * A D_{o k}\right]
$$

Subject to:

$$
\begin{aligned}
& A 0_{k s}=\text { stock }_{k s}-\sum_{o} D_{o k} * U 0_{o k s} \quad \forall k, s \\
& A_{k s t}=\beta_{k s} * m p s_{k t}-\sum_{o} D_{o k} * U_{o k s t} \quad \forall k, s, t \\
& \sum_{s} U 0_{o k s}+\sum_{s} \sum_{t} U_{o k s t}=Y K_{o k} \quad \forall o, k \\
& \sum_{t}^{s}\left(D K_{o k t} * t\right) \geq d d_{o} * Y K_{o k} \quad \forall o, k \\
& \sum_{t}^{t}\left(D K_{o k t} * t\right)=d d_{o} * Y K_{o k}+L D K_{o k} \quad \forall o, k \\
& L D K_{o k} \leq \operatorname{maxd}_{o} \quad \forall o, k \\
& \sum_{t} D K_{o k t} \leq 1 \quad \forall o, k \\
& A D_{\text {ok }}=\sum_{t}\left(D K_{\text {okt }} * t\right)-\sum_{s} \sum_{t} U_{\text {okst }} * t-\sum_{s} U 0_{o k s} \quad \forall o, k \\
& A 0_{k s}, A_{\text {kst }} \text { Continuous } \\
& A D_{o k}, L D K_{o k} \text { Integer } \\
& Y K_{o k}, D K_{\text {okt }}, U_{\text {okst }}, U 0_{\text {oks }} \text { Binary }
\end{aligned}
$$

Equation (2) calculates the uncommitted quantity of a product $k$ and subtype $s$ available in stock after reallocating orders. This quantity equals the real stock of this product $k$ and subtype $s$, minus the customer order lines served with such stock. Similarly, Equation (3) computes the uncommitted planned quantity of a product $k$ and subtype $s$ available during period $t$ after reallocating orders. This quantity equals the planned quantity of this product and the subtype to be produced during time period $t$, minus the customer order lines served with product $k$ and subtype $s$ through it. Equation (4) ensures serving each order line from a particular homogeneous quantity (subtype), while Equation (5) ensures serving an order if the delivery of all its order lines is complete. This means that it is not possible to serve only some order lines or part of the order line quantities. Moreover, Equations (5)-(7) guarantee that the delivery of an order line takes place within the date range specified by the committed due date and the maximum delay allowed. Equation (8) indicates serving an order line only during one period of time. Equation (9) determines which products we reserve during the periods of time until their delivery date. Finally, Equation (10) defines the nature of each variable by distinguishing binary, continuous or integer variables.

\section{SD model formulation}

In order to develop the system dynamics model to reallocate available homogeneous products to committed orders, we used the following methodology: i) propose the casualloop diagram; ii) create the flow chart that represents the process, iii) generate the equations that define the system dynamics model's behaviour; iv) validate and perform the system dynamics model to evaluate what-if scenarios and sensitivity analyses. 
The causal-loop diagram (Figure 2) shows the cause-effect relations between the different system elements, which help to understand them and to subsequently draw the flow chart of the inventory reallocation model. Arrows depict these relations. Arrows take a positive sign if the two variables are directly proportional, namely a change in the origin variable leads to a change in the destination variable in the same sense. An arrow relates elements, otherwise the relation between the two variables is inversely proportional and the arrow takes a negative sign.

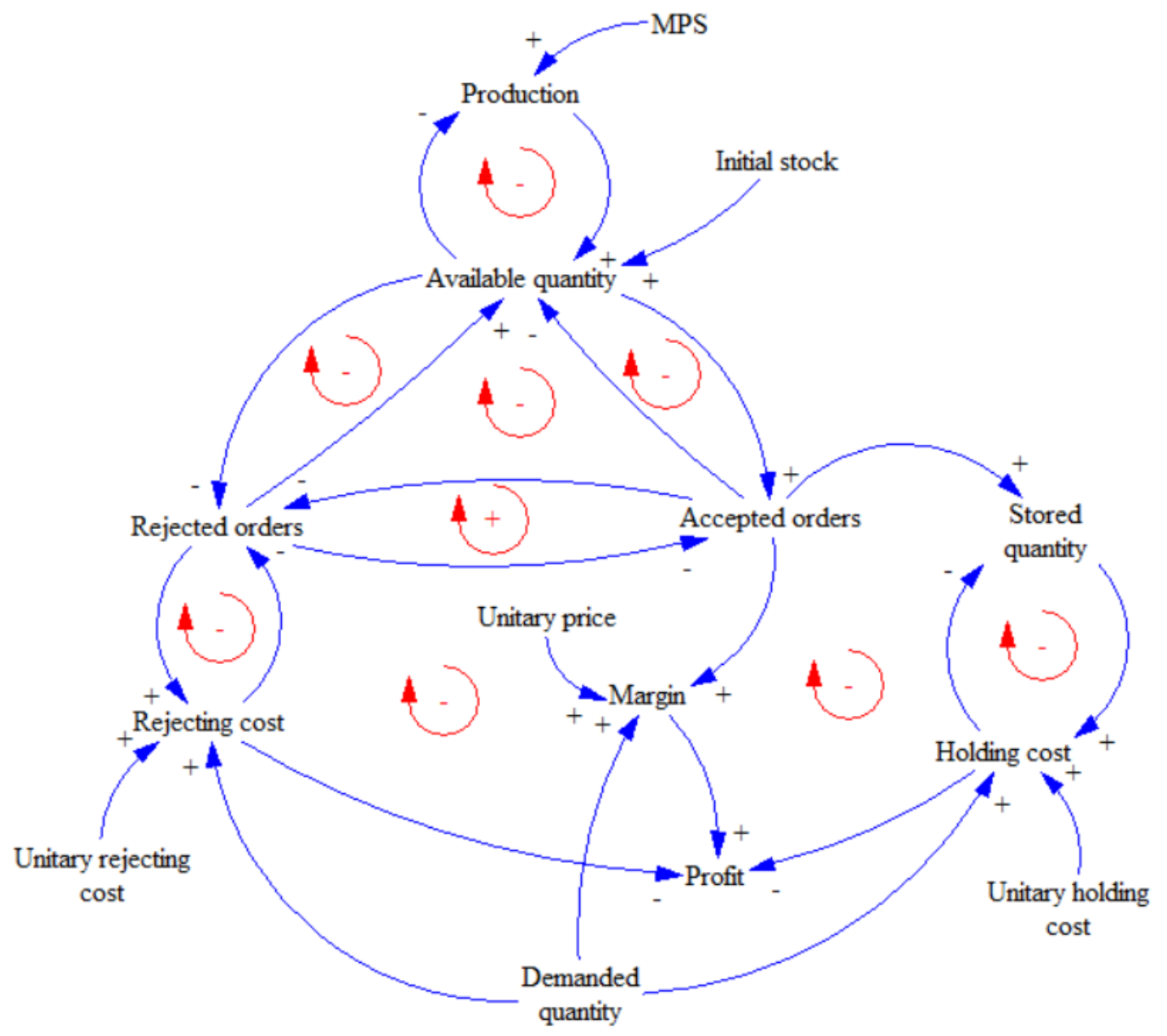

Figure 2. The casual-loop diagram of the reallocation process

As the causal-loop diagram shows, the quantity planned to be produced in the MPS determines production. The produced quantities form part of the available quantity of product, which demonstrates their positive relation. When any simulation of this system starts, a quantity of available product remains in the warehouse that comprises the initial stock. So the larger the initial stock, the more the available quantity.

In the process followed to reallocate available quantities to committed orders, we see that the relation between the available quantities of product and accepted orders is positive (the bigger the quantity of available product, the more committed orders served), while the relation between the available quantities of product and orders rejected is negative (the bigger the quantity of available product, the fewer committed orders rejected). We can also read these relations in the reverse; the more committed orders served, the smaller quantity of available product that remains. Similarly, the more orders rejected, the bigger the quantity of available product that remains. A relation exists between accepted and 
rejected orders since the accepted quantity of orders increases when the rejected quantity of orders reduces, which establishes a negative relation. Moreover, when the quantity of accepted committed orders increases, it is necessary to reserve a bigger quantity of product beforehand until the committed due date of the order.

Regarding margin, we observe that the number of served orders and the quantity of products demanded in such orders have a positive impact on the margin to be obtained. The margin is also directly proportional to the unitary price of each product. Similarly, the costs of rejecting orders increase when the unitary costs of rejecting a product rise, and also with the number of rejected orders and the quantity of demanded products in such orders.

The holding costs derive from reserving MPS quantities of product until their due date. Holding costs may be null if the intended quantity of product to serve a particular order proceeds from the MPS that corresponds to the period of time which coincides with customers' due dates. Similarly, holding costs may be null when serving the customer order with a delay. Therefore, holding costs increase with the quantity of reserved products, and also with the unitary holding cost per product.

Finally, the company's total profit increases when the obtained margin goes up. In turn, the total profit goes down when the costs from rejecting orders or from storing a reserved product increase.

The closed chains of relations between variables results in loops, which can be positive or negative. Negative loops act like system stabilisers as they lead the system to a specific objective. However, positive loops have the opposite effect on the system. The dominance of negative or positive loops determines the system's final performance. In this case, the causal-loop diagram shows that the system is hyperstable as the vast majority of its loops (all except one) are negative. With the causal-loop diagram, one can develop a flow chart or a Forrester diagram. This diagram represents the system under study and allows the simulation of the shortage planning problem. For this purpose, we first identify the level, flow and auxiliary variables needed to define the Forrester diagram. Table 3 offers the notation and respective units of measure, where index $o$ refers to the customer order, index $k$ denotes the product and index $s$ represents the product subtype.

Table 3. Nomenclature

\begin{tabular}{|l|l|}
\hline \multicolumn{2}{|l|}{ Level variables } \\
\hline$A Q W_{k S}$ & Available quantity of finished product $k$ and subtype $s\left(\mathrm{~m}^{2}\right)$ \\
\hline$R Q W_{o k}$ & $\begin{array}{l}\text { Reserved quantity of finished product } k \text { to serve the customer order } o \text { on its committed due } \\
\text { date } d d_{o}\left(\mathrm{~m}^{2}\right)\end{array}$ \\
\hline$D_{o k}$ & Quantity of product $k$ demanded in customer order $o$ \\
\hline$D S_{k}$ & Total quantity of demand of product $k$ served to customers $\left(\mathrm{m}^{2}\right)$ \\
\hline$D R_{k}$ & Total quantity of demand of product $k$ rejected to customers $\left(\mathrm{m}^{2}\right)$ \\
\hline$C O L_{o k}$ & Committed order lines during the OP process (Dmnl) \\
\hline$A O L$ & Total number of accepted order lines during the inventory reallocation process (Dmnl) \\
\hline$R O L$ & Total number of rejected order lines during the inventory reallocation process (Dmnl) \\
\hline$P$ & Total profit $(€)$ \\
\hline$H C$ & Total holding cost of the quantities reserved $(€)$ \\
\hline$R C$ & Total rejecting cost $(€)$ \\
\hline Flow variables \\
\hline
\end{tabular}




\begin{tabular}{|c|c|}
\hline$A Q_{k s}$ & Available quantity of product $k$ and subtype $s$ during each period of time ( $\mathrm{m}^{2} /$ week $)$ \\
\hline$R Q_{o k s}$ & $\begin{array}{l}\text { Reserved quantity of finished product } k \text { and subtype } s \text { during each period of time to serve } \\
\text { the customer order } o \text { on its committed due date } d d_{o}\left(\mathrm{~m}^{2} / \text { week) }\right.\end{array}$ \\
\hline$S Q_{o k}$ & $\begin{array}{l}\text { Served quantity of finished product } k \text { to customer order } o \text { during each period of time } \\
\left(\mathrm{m}^{2} / \mathrm{week}\right)\end{array}$ \\
\hline$S Q^{\prime}{ }_{o k s}$ & $\begin{array}{l}\text { Served quantity of finished product } k \text { with subtype } s \text { to customer order } o \text { during each period } \\
\text { of time }\left(\mathrm{m}^{2} / \text { week }\right)\end{array}$ \\
\hline$D Q_{o k}$ & Demanded quantity of product $k$ in a customer order $o$ during each period of time $\left(\mathrm{m}^{2} /\right.$ week $)$ \\
\hline$R D_{o k}$ & Rejected demand of product $k$ in a customer order $o$ during each period of time $\left(\mathrm{m}^{2} /\right.$ week $)$ \\
\hline$S D_{o k}$ & Served demand of product $k$ in a customer order $o$ during each period of time $\left(\mathrm{m}^{2} /\right.$ week $)$ \\
\hline$A L_{o k}$ & $\begin{array}{l}\text { Identifies if the delivery of product } k \text { of order } o \text { is accepted during a period of time } \\
(\text { Dmnl/week) }\end{array}$ \\
\hline$R L_{o k}$ & $\begin{array}{l}\text { Identifies if the delivery of product } k \text { of order } o \text { is rejected during this period of time } \\
\text { (Dmnl/week) }\end{array}$ \\
\hline$W M$ & Total margin obtained during each period of time (€/week) \\
\hline WHC & Total holding cost of the quantities reserved during each period of time ( $€ /$ week) \\
\hline$W R C$ & Total rejecting cost during each period of time ( $€ /$ week $)$ \\
\hline \multicolumn{2}{|c|}{ Auxiliary variables } \\
\hline$\beta_{k s}$ & $\begin{array}{l}\text { Coefficient of homogeneity or percentage of a lot of product } k \text { which will be subtype } s \text { after } \\
\text { production (Dmnl) }\end{array}$ \\
\hline$m p s_{k}$ & Planned quantity of finished product $k\left(\mathrm{~m}^{2}\right)$ \\
\hline $\operatorname{prod}_{k s}$ & Produced quantity of finished product $k$ with subtype $s\left(\mathrm{~m}^{2}\right)$ \\
\hline stock $_{k s}$ & Total available stock of subtype $s$ of finished product $k\left(\mathrm{~m}^{2}\right)$ \\
\hline $\operatorname{dem}_{o k}$ & Quantity demanded of product $k$ by customer order $o\left(\mathrm{~m}^{2}\right)$ \\
\hline$d d_{o}$ & Committed due date of customer order $o$ (week) \\
\hline $\operatorname{maxd}_{o}$ & Maximum delay allowed for customer order $o$ in relation to committed due date $d d_{o}$ (week) \\
\hline$h c_{k}$ & Inventory holding costs per unit of product $k$ and period of time $\left(€ / \mathrm{m}^{2} /\right.$ week $)$ \\
\hline$r c_{k}$ & Rejecting cost per unit of product $k\left(€ / \mathrm{m}^{2}\right)$ \\
\hline$p_{k}$ & Price per unit of product $k\left(€ / \mathrm{m}^{2}\right)$ \\
\hline$A Q A_{\text {oks }}$ & Identifies if an order $o$ is committed with a certain product $k$ and subtype $s$ (Dmnl) \\
\hline
\end{tabular}

Figure 3 depicts the flow chart of the inventory reallocation model that adapts to the real system. This model is good for running experiments to study the system's performance in different scenarios. The Vensim ${ }^{\circledR}$ simulation software implements the model. To this end, we design the equations that define the performance of each level and flow variable, and we assign the values that correspond to the auxiliary variables.

We now go on to briefly describe the notation employed to represent the model:

- The flow variables notation is accompanied by $(t)$, which denotes that the value of such variables depends on each period of time.

- Level variables represent the addition or subtraction of different flow variables over time, represented in this notation by the integral, from the beginning of the simulation to the corresponding period of time, of the addition or subtraction of flow variables. The level variables notation comes with $(t)$, which denotes that the value of such variables depends on each period of time.

- We use nested braces to represent "if...then...else" decisions. It is possible to concatenate several "if...then...else" decisions by representing a nested brace inside another nested brace. 




Figure 3. Flow chart of the reallocation process 
This model's performance commences as follows: when simulation starts, the only available quantities of product are those that comprise the initial stock. During the following periods of time, homogeneous quantities of product become available when produced. The planned quantities of product in the MPS define production, as does the coefficient of homogeneity that defines the homogeneity between units of manufactured products.

At the beginning of simulation, a set of committed orders is known. The model has information about the products demanded in each order, the demanded quantities, the agreed due date, and the maximum delivery delays allowed. During the first period of time no order line is served nor rejected.

For each order line, and during each period of time, the model verifies if it is necessary to serve each one with a particular available amount of product (defining the homogeneous subtype). During this allocation, if the current time period comes before the agreed due date, it is necessary to reserve these quantities until the due date. If the current period of time is equal to or is later than the due date, it is necessary to check if the maximum delays allowed has been exceeded. If this were the case, it is necessary to reject the customer order line, otherwise we must directly serve the customer order line.

At the same time, we need to update the counters for the number of accepted or rejected committed order lines as their demand is accepted or rejected. Similarly, we update the economic data during simulation to obtain the total profit made by the company.

More details about the model's performance are available with the explanation of the equations that comprise it. Equations (12)-(24) determine the system's performance. However, the other equations are useful for analysing the system's performance. Equation (12) defines the quantity of product to be produced during each period of time, calculated by multiplying the quantity of product planned to be produced in the MPS for each period of time and the homogeneity coefficient. This coefficient characterises the distribution of a production lot into homogeneous sublots.

$\operatorname{prod}_{k s}=m p s_{k} * \beta_{k s}$

Equation (12) calculates the value for flow variable $A Q_{k s}$ for each period of time.

$A Q_{k s}(t)=\left\{\begin{array}{l}\text { stock }_{k s}, \text { if } t=0 \\ \operatorname{prod}_{k s}, \text { otherwise }\end{array} \quad \forall k, s\right.$

We used level variable $A Q W_{k s}$ to know the exact units of each product and each subtype available per period of time. This acts as a virtual warehouse of available quantities because it does not really exist, but displays the same performance as a real warehouse. Equation (14) defines $A Q W_{k s}$ as the available quantities that arrive at the virtual warehouse, less the quantities used to serve or reserve orders.

$A Q W_{k s}(t)=\int_{t_{0}}^{t}\left[A Q_{k s}(t)-\sum_{o}\left(R Q_{o k s}(t)+S Q^{\prime}{ }_{o k s}(t)\right)\right] d t ; \quad A Q W_{k s}\left(t_{0}\right)=0 \quad \forall k, s$

We include variable $A Q A_{o k s}$ for its use during the model's validation by detailing which order is to be served and with which product and subtype.

Variable $S Q^{\prime}{ }_{\text {oks }}$ represents the quantity of product with a specific subtype, served directly from the available quantities in the virtual warehouse. We can serve a quantity directly if 
the current period of time equals or is after the agreed due date. We calculate flow variable $S Q^{\prime}{ }_{o k s}$ as indicated in Equation (15).

$S Q^{\prime}{ }_{o k s}(t)=\left\{\begin{array}{l}\text { if } t \geq d d_{o} \begin{array}{l}\text { if } A Q A_{\text {oks }}=1 \\ 0, \text { otherwise }\end{array} \\ 0, \text { otherwise }\end{array} \quad \forall o, k, s\right.$

Equation (16) represents the reserve of a quantity of product with a specific subtype to serve a particular order on its due date, $R Q_{o k s}$. It is only possible to reserve a quantity to serve an order if the current period of time is before the agreed due date.

$R Q_{o k s}(t)=\left\{\begin{array}{l}\text { if } t<d d_{o}\left\{\begin{array}{l}\text { if } A Q A_{\text {oks }}=1 \\ 0, \text { otherwise }\end{array}\right. \\ 0, \text { otherwise }\end{array} \quad \forall o, k, s\right.$

Equation (17) defines $R Q W_{o k}$ as the reserved quantities that arrive from the virtual warehouse of available quantities, less the quantities used to serve orders.

$R Q W_{o k}(t)=\int_{t_{0}}^{t}\left[\sum_{S} R Q_{o k s}(t)-S Q_{o k}(t)\right] d t ; \quad R Q W_{o k}\left(t_{0}\right)=0 \quad \forall o, k$

Variable $S Q_{o k}$ represents the quantity of product served to customers after being reserved for one period of time or more. We can only serve a quantity if the current period of time equals or is after the agreed due date. We define $S Q_{o k}$ as stated in Equation (18).

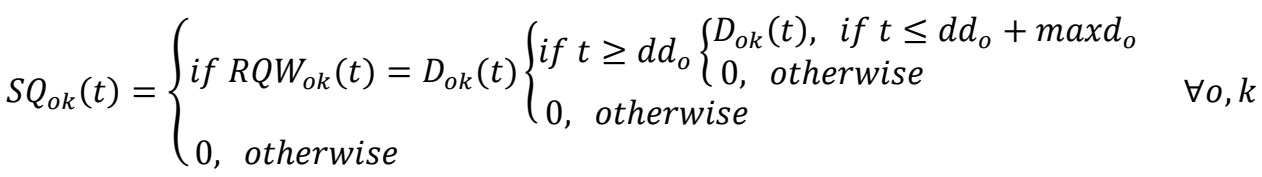

Note that both variables $S Q^{\prime}{ }_{o k s}$ and $S Q_{o k}$ indicate the quantity of products that we must serve to customers during each period of time. However, these variables are not the same. When talking about variable $S Q^{\prime}{ }_{\text {oks }}$, we directly serve orders from the available product quantities. However when we refer to variable $S Q_{o k}$, we first reserve the product quantities to serve each order until their due date, and then we serve these products.

Equation (19) assigns the quantities demanded for each order and particular product to variable $D Q_{o k}$.

$D Q_{o k}(t)=\operatorname{dem}_{o k} \quad \forall o, k$

Flow variable $R D_{o k}$ represents the quantity of rejected product during each period of time per order. Equation (20) determines that, if the demand of a product in a particular order exceeds zero, then we must check if the current period of time equals the last period of time of the simulation horizon. If this condition is met, demand is rejected if not served during this period of time. However, if the current period of time does not equal the last period of time of the simulation horizon, and is less than or equals the agreed due date, plus the maximum delays allowed, the demand is also rejected.

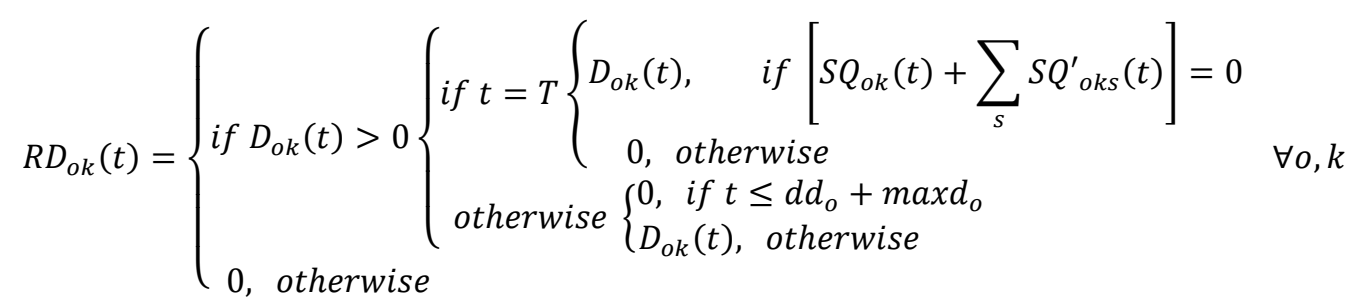


Flow variable $S D_{o k}$ determines the quantity of product served to customers during each period of time per order. We calculate the served demand presented in Equation (21) as the sum of the both variables and show the served quantities of product per order $\left(S Q^{\prime}{ }_{o k s}\right.$ and $\left.S Q_{o k}\right)$.

$S D_{o k}(t)=S Q_{o k}(t)+\sum_{S} S Q_{o k s}^{\prime}(t) \quad \forall o, k$

We employ level variable $D_{o k}$ to know the existing demand of products during each period of time. Equation (22) defines $D_{o k}$ as the new demand that arrives during each period of time, minus the rejected and served demands for each period of time.

$D_{o k}(t)=\int_{t_{0}}^{t}\left[D Q_{o k}(t)-R D_{o k}(t)-S D_{o k}(t)\right] d t ; \quad D_{o k}\left(t_{0}\right)=0 \quad \forall o, k$

We use the level variable called $D S_{k}$ to control the total quantity of demanded product served to customers (23).

$D S_{k}(t)=\int_{t_{0}}^{t}\left[\sum_{o} S D_{o k}(t)\right] d t ; \quad D S_{k}\left(t_{0}\right)=0 \quad \forall k$

Similarly, we employ the level variable called $D R_{k}$ to control the total quantity of rejected demanded product (24).

$D R_{k}(t)=\int_{t_{0}}^{t}\left[\sum_{o} R D_{o k}(t)\right] d t ; \quad D R_{k}\left(t_{0}\right)=0 \quad \forall k$

Equations (25) - (29) establish the control of the number of served/rejected order lines. Flow variable $A L_{o k}$ determines the period of time when an order line has been accepted/served as shown in Equation (25).

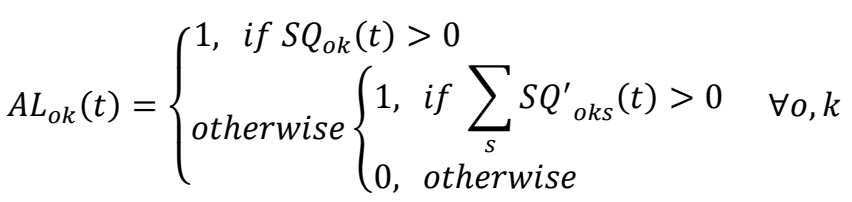

Flow variable $R L_{o k}$ determines the period of time when an order line is rejected as shown in Equation (26).

$R L_{o k}(t)=\left\{\begin{array}{ll}1, & \text { if } R D_{o k}(t)>0 \\ 0, & \text { otherwise }\end{array} \quad \forall o, k\right.$

At the start of simulation, we commit all the known order lines, and the value of binary variable $C O L_{o k}$ equals one for all the existing orders and order lines. As shown in (27), the variable takes a value that equals zero when an order line is rejected or served.

$\operatorname{COL}_{o k}(t)=\int_{t_{0}}^{t}-\left[A L_{o k}+R L_{o k}\right] d t ; \quad \operatorname{COL}_{o k}\left(t_{0}\right)=1 \quad \forall o, k$

Level variables $A O L$ and $R O L$ are useful for measuring the total number of accepted or rejected order lines, respectively. Equation (28) shows that the total number of accepted order lines equals those per period of time. Similarly, Equation (29) indicates that the total number of rejected order lines equals these per period of time.

$A O L(t)=\int_{t_{0}}^{t}\left[\sum_{o} \sum_{k} A L_{o k}(t)\right] d t ; \quad A O L\left(t_{0}\right)=0$ 
$R O L(t)=\int_{t_{0}}^{t}\left[\sum_{o} \sum_{k} R L_{o k}(t)\right] d t ; \quad R O L\left(t_{0}\right)=0$

Equations (30) - (35) provide the economic results obtained during simulation. Equation (30) defines the margin obtained by serving customer orders during each period of time. This we calculate as the total demand served per unitary price of each product type.

$W M(t)=\sum_{o} \sum_{k} S D_{o k}(t) * p_{k}$

Equation (31) defines the holding costs of reserving products allocated to order lines until their due date per period of time.

$W H C(t)=\sum_{o} \sum_{k} R Q W_{o k}(t) * h c_{k}$

Equation (32) defines the rejection costs obtained by rejecting customer orders during each period of time.

$W R C(t)=\sum_{o} \sum_{k} R D_{o k}(t) * r c_{k}$

Profit $(P)$ is the level variable to maximise, which we calculate as shown in Equation (33).

$P(t)=\int_{t_{0}}^{t}[W M(t)-W H C(t)-W R C(t)] d t ; \quad P\left(t_{0}\right)=0$

Finally, Equation (34) and Equation (35) present the total holding costs and the total rejecting costs.

$$
\begin{aligned}
H C(t) & =\int_{t_{0}}^{t}[W H C(t)] d t ; \quad H C\left(t_{0}\right)=0 \\
R C(t) & =\int_{t_{0}}^{t}[W R C(t)] d t ; \quad R C\left(t_{0}\right)=0
\end{aligned}
$$

Moreover, we identify the key element of this system's performance and, therefore, the element on which improvement proposals focus, as variable $A Q A_{o k s}$ because this variable determines which order lines we serve and which product subtypes we can serve these lines with. This decision conditions the system's performance for several reasons, which depend on: (i) the rule used to reallocate available quantities to committed orders, when we can serve more or fewer order lines; (ii) if we accept order lines, we can make more or less profit (this also implies a higher or lower cost of rejecting order lines); (iii) the product subtype chosen to serve an order line allows us to serve this order line with or without delay; (iv) with the product subtype chosen to serve an order line, we can serve more or fewer orders because of homogeneity requirements.

\section{Applying the system dynamics model}

We employed data based on a real Spanish ceramic company's problem to define the different types of variables. We also considered the assumptions set out below while simulating the model: 
- The simulation run length is the equivalent to 12 periods of time, where each period of time represents 1 week.

- The company's objective consists of maximising the profits made after reallocating the available quantities to previously committed orders.

- We contemplated 35 orders made up of 10 order lines with 10 different products.

- Each order line requires a quantity of between 20 and $4,000 \mathrm{~m}^{2}$ of the final product, and total demand is approximately $52,200 \mathrm{~m}^{2}$ of the product.

- When simulation commences, we know the product quantity available in the warehouse, which we classify according to the homogeneous subtype to which it belongs.

- We cannot classify the quantities planned in the MPS into homogeneous sublots before their manufacturing. In this case, we estimate the distribution of a lot into homogeneous subtypes according to probabilistic distributions.

- The customer requires homogeneity among all the units that each particular order line comprises.

- We need to serve customers orders within the time interval defined by the committed due date during the OP processing, and the maximum delay detailed by the customer.

- The customer allows us to make the same number of deliveries as the number of lines that the order includes. However, partial deliveries of order lines are not possible.

Table 4 presents the economic data per unit of each product.

Table 4. The economic data of each product

\begin{tabular}{|c|c|c|c|}
\hline $\begin{array}{c}\text { Final } \\
\text { product } \\
(\boldsymbol{k})\end{array}$ & $\begin{array}{c}\text { Unitary } \\
\text { margin } \\
\left(p_{k}\right)\end{array}$ & $\begin{array}{c}\text { Unitary } \\
\text { rejecting cost } \\
\left(r c_{k}\right)\end{array}$ & $\begin{array}{c}\text { Unitary } \\
\text { holding cost } \\
\left(\boldsymbol{h} c_{k}\right)\end{array}$ \\
\hline 1 & 7.00 & 5.25 & 0.064 \\
\hline 2 & 18.00 & 13.50 & 0.052 \\
\hline 3 & 12.00 & 9.00 & 0.040 \\
\hline 4 & 10.00 & 7.50 & 0.036 \\
\hline 5 & 5.00 & 3.75 & 0.036 \\
\hline 6 & 11.00 & 8.25 & 0.052 \\
\hline 7 & 13.00 & 9.75 & 0.040 \\
\hline 8 & 12.00 & 9.00 & 0.036 \\
\hline 9 & 6.00 & 4.50 & 0.052 \\
\hline 10 & 15.00 & 11.25 & 0.045 \\
\hline
\end{tabular}

Additionally, we set the initial value for level variable $C O L_{o k}$ to 1 , while the rest of the level variables take a null initial value.

\subsection{Validation}

We ran several of the tests proposed by Sterman (2000) to validate the contemplated model. The first one was the dimensional consistency test, which checks that the measure units employed in the model are correct. Secondly, we ran the reproduction test of known performances. The computer used to solve the models has an Intel ${ }^{\circledR}$ Xeon® CPU E5- 
$1620 \mathrm{v} 2 @ 3.70 \mathrm{GHz}$ processor, with an installed capacity of $32 \mathrm{~GB}$ and a 64-bits operating system. We achieved the results obtained by mathematical programming with the MPL ${ }^{\circledR}$ tool and solver Gurobi ${ }^{\mathrm{TM}}$ 6.0.4, whereas we ran simulation in Vensim ${ }^{\circledR}$. We used the same input data for both tests. Moreover, in the simulation model, the auxiliary variable Available quantity allocation $\left(A Q A_{o k s}\right)$ indicated with which subtype we must serve each order line. Afterwards, we obtained the results that appear in Table 5, which we used to validate the model. Thirdly, we ran an extreme-conditions test in two situations: no existing demand and no existing production.

Table 5. Comparison of the mathematical programming and system dynamics results (35 orders)

\begin{tabular}{|c|r|r|}
\hline Variable & $\begin{array}{c}\text { Mathematical } \\
\text { programming }\end{array}$ & $\begin{array}{c}\text { System } \\
\text { dynamics }\end{array}$ \\
\hline$A O L$ & 286 & 286 \\
\hline$R O L$ & 64 & 64 \\
\hline$H C$ & $1,981.38 €$ & $1,981.00 €$ \\
\hline$R C$ & $171,233.25 €$ & $171,200.00 €$ \\
\hline$\sum_{t} W M$ & $308,561.00 €$ & $308,554.00 €$ \\
\hline$P$ & $135,346.37 €$ & $135,300.00 €$ \\
\hline Resolution time & $33.18 \mathrm{sec}$ & $38 \mathrm{sec}$ \\
\hline
\end{tabular}

We carried out an additional test to compare the results obtained by the mathematical programming model and the system dynamics model. The intention of this test is to compare their performance for larger problems. For this case, we contemplated 70 orders and we duplicated the data about the MPS and initial stocks. The results (Table 6) show that the mathematical programming model needs almost 10 hours to provide a solution, whereas the system dynamics model instantaneously gives a solution.

Table 6. Comparison of the mathematical programming and system dynamics results (70 orders)

\begin{tabular}{|c|r|r|}
\hline Variable & $\begin{array}{c}\text { Mathematical } \\
\text { programming }\end{array}$ & $\begin{array}{c}\text { System } \\
\text { dynamics }\end{array}$ \\
\hline$A O L$ & 578 & 578 \\
\hline$R O L$ & 122 & 122 \\
\hline$H C$ & $€ 2,500.5$ & $€ 2,496$ \\
\hline$R C$ & $€ 630,598.5$ & $€ 330,600$ \\
\hline$\sum_{t} W M$ & $€ 299,847$ & $€ 632,946$ \\
\hline$P$ & & \\
\hline Resolution time & $9 \mathrm{~h} \mathrm{13} \mathrm{min} 20 \mathrm{sec}$ & $40 \mathrm{sec}$ \\
\hline
\end{tabular}


The mathematical programming model has also been solved for an instance of data comprised by 140 orders. In this case, a near to the optimum solution has been found in 48 hours, with a GAP of $0.17 \%$. This GAP represents the difference between the best solution found and the best bound. However, after 96 hours of execution, the GAP has not decreased. Computational results show how the time needed to solve the MILP model increases with the number of already committed orders.

\subsubsection{Sensitivity analysis}

With the sensitivity analysis, we examined the model's performance by modifying the values assigned to its constant parameters. In this model, one parameter in particular can substantially change the model's performance, which can actually imply a certain degree of uncertainty. This parameter is $\beta_{k s}$, which represents the distribution of a lot into homogeneous sublots. We carried out a Monte Carlo sensitivity analysis on this parameter, where we assigned the distribution function to follow, as well as its minimum and maximum values. We studied the effects that these changes had on level variables Profit (Figure 4) and Accepted Order Lines (Figure 5). It is important to note that the first four weeks belong to the warm up simulation period. As we contemplated only 13 periods of time, we did not achieve the steady state with the Profit level variable because the profit calculations were higher than costs on the simulation horizon. Nevertheless, the average profit reached the steady state, as shown in Figure 6. With the Accepted Order Lines, as it is a level variable, it accumulates the accepted orders without reaching a steady state. Figure 7 presents the average Accepted Order Lines where the steady state is reached.

Considering that a robust model maintains a fixed design and still accommodates plenty of changes of uncontrollable environmental factors, we were able to ensure the model's robustness as the decision made about product allocation to orders was limited. We verified this robustness when we observed that the values obtained by a sensitivity analysis for the studied level variables were lower than those initially obtained. This was because not enough homogeneous product was available when assigning the different values to the homogeneity coefficient to serve some order lines that could be served beforehand. Thus we made less profit and served fewer order lines, which are the results that we expected of the model. Although we carried out other sensitivity tests with several parameters (maximum deliveries allowed, initial stock, etc.), we conclude that they had no significant effect on the model and the homogeneity coefficient had the strongest impact on LHP. Due to space requirements, we do not provide these sensitivity analyses here. 


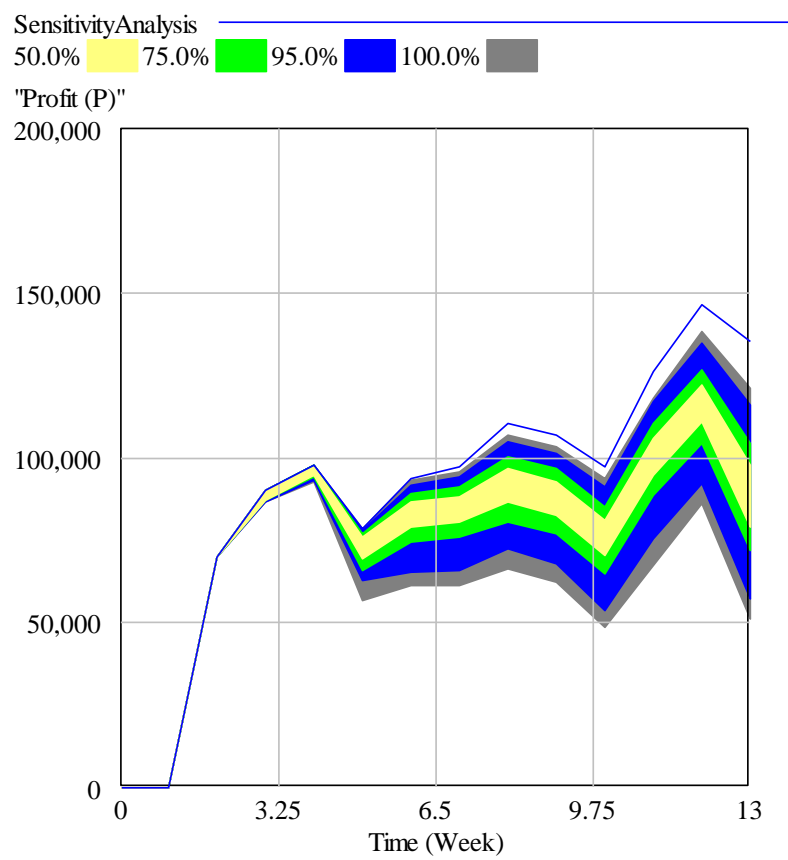

Figure 4. Profit. Sensitivity analysis

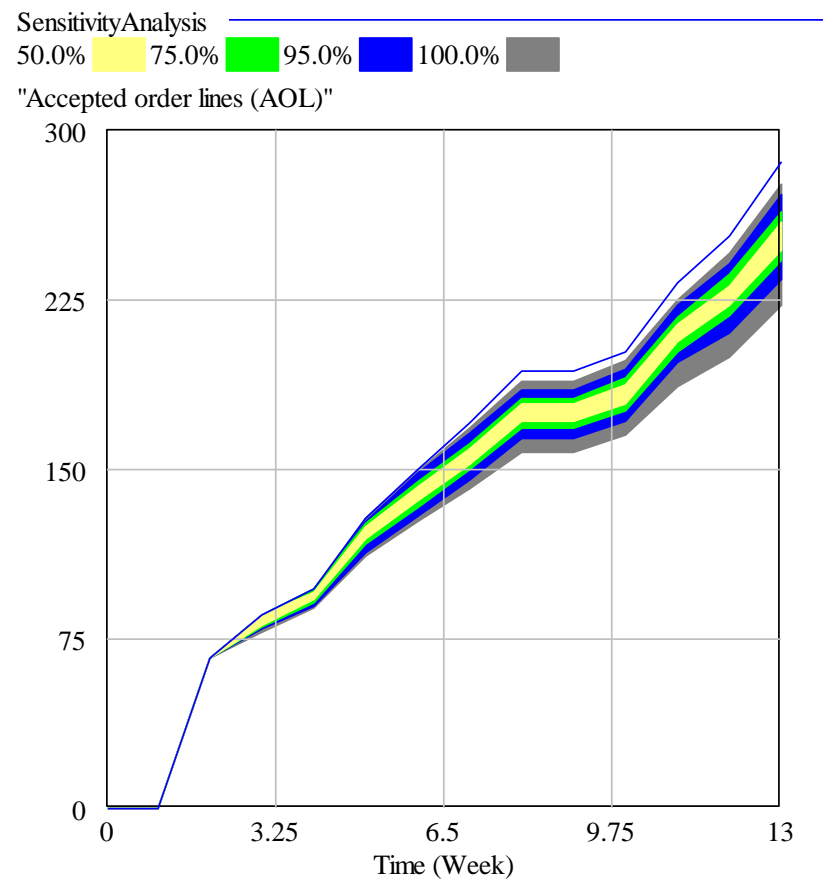

Figure 5. Accepted order lines. Sensitivity analysis 


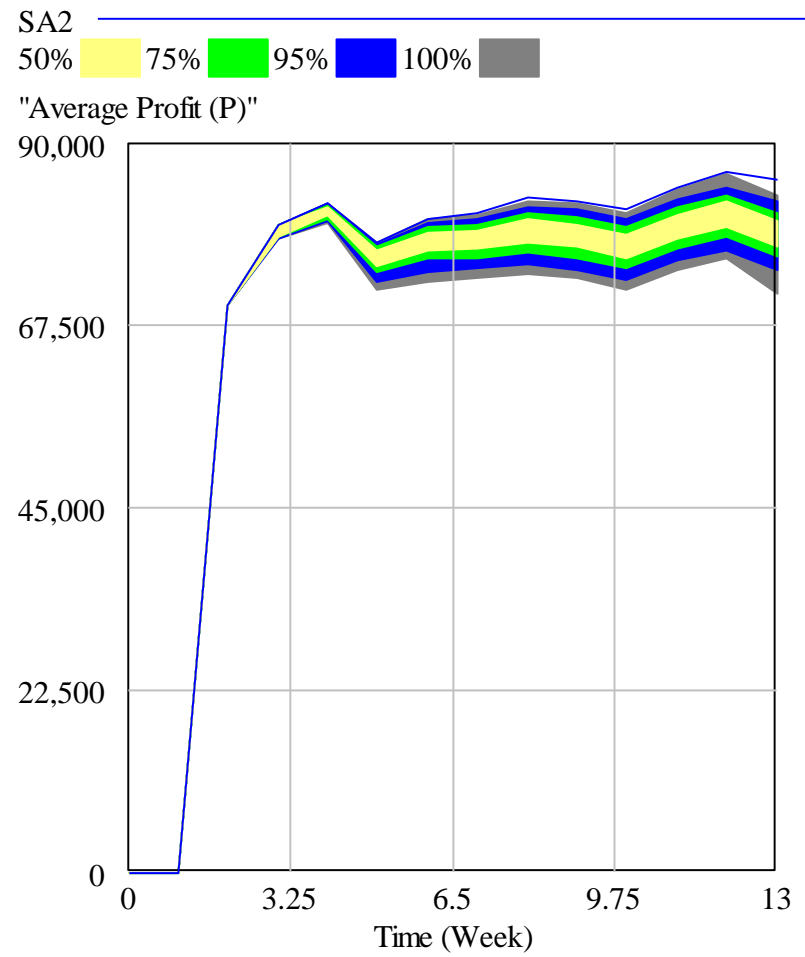

Figure 6. Average profit. Sensitivity analysis

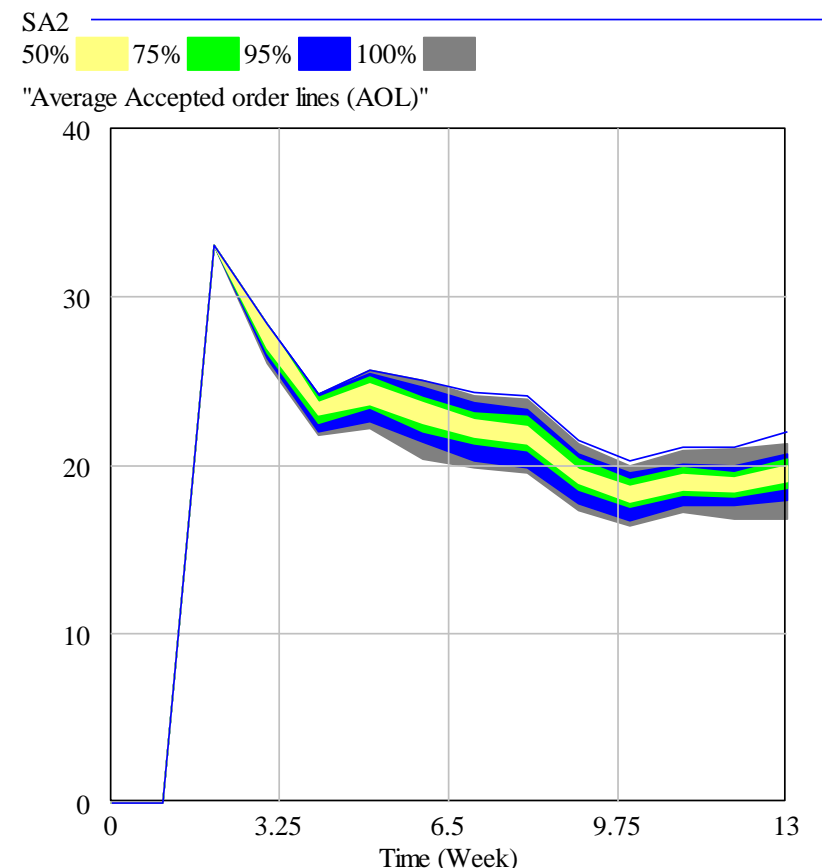

Figure 7. Average accepted order lines. Sensitivity analysis

\subsection{Simulating scenarios}

We propose a series of scenarios that intend to improve the method, according to which we allocate the available quantities to previously committed orders. Up to this point, we did this with auxiliary variable $A Q A_{\text {oks }}$, which we deleted from the model and we used a different method to allocate the available quantities to committed orders. In Scenario 1, we considered serving the committed by the available quantities. This means reserving no product quantities and, therefore, holding costs always equal zero. 
Flow variable $S Q_{\text {oks }}^{\prime}$ defines the relation between the available quantities of homogeneous product and committed orders. Then we need to reformulate the equation that determines the performance of this variable. During the reallocation process, we made the decisions presented in (36): if the current period comes before the due date, we do not serve the order line. However, if the current time period comes after the range of dates defined by the committed due date and the maximum deliveries allowed, then we do not serve the order line. If we have already served this order line during the same period of time, but with a different homogeneous subtype, we cannot serve the order line. If the available quantity of product is greater than or equals the sum of the order line demand, plus the quantity of available product destined to serve other orders, then we serve the order lines with the product that has this homogeneous subtype.

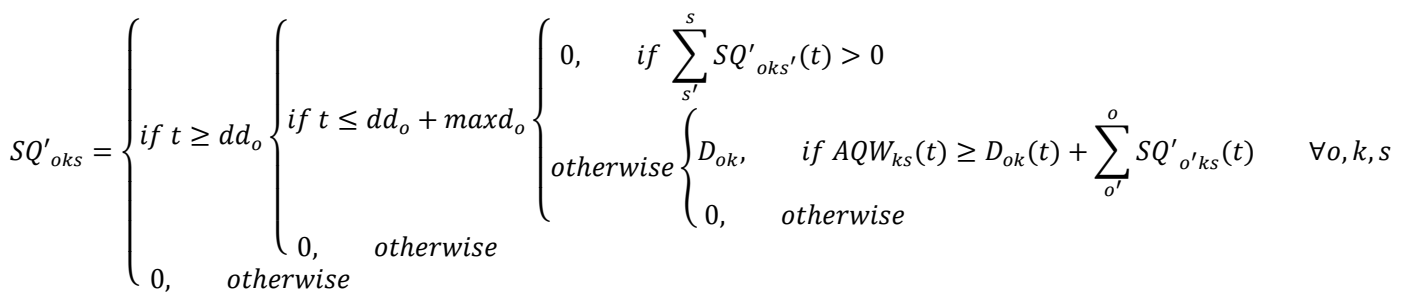

This equation must represent each order, product and subtype, and 1,260 equations (35 orders $\cdot 10$ products $\cdot 36$ subtypes) would constitute flow variable $S Q^{\prime}{ }_{o k s}$.

Based on the system considered in Scenario 1, we ran two experiments in which the company's policies about delivering orders changed. Scenario 2 contemplates what would happen if the company did not allow delays in order deliveries. Scenario 3 recreates a situation in which there is no maximum allowable delay, but it is possible to serve orders until the end of the simulation horizon. The intention of these scenarios is to assess the influence that flexibility in deliveries would have on the assessed system.

Subsequently, we propose three experiments in which the homogeneity coefficient (distribution of a production lot into homogeneous sublots) changes. For this purpose, the values assigned to auxiliary variable $\beta_{k s}$ vary. We consider each production lot to be divided into three homogeneous sublots. Then we define the homogeneity coefficient as $\beta_{k s}=\beta_{k 1}-\beta_{k 2}-\beta_{k 3}$, where $\beta_{k 1}, \beta_{k 2}$, and $\beta_{k 3}$ are the proportion of the production lot classified as homogeneous subtypes 1, 2, or 3 respectively. In Scenario 1, we divide each production lot into three unbalanced homogeneous sublots, and by following distribution $\beta_{k s}=0.7-0.2-0.1$ in Scenario 4, we obtain a single homogeneous lot after production $\left(\beta_{k s}\right.$ $=1.0-0.0-0.0)$. In Scenario 5, we obtain two balanced homogeneous sublots with a production lot $\left(\beta_{k s}=0.5-0.5-0.0\right)$ and, to finish, we obtained three unbalanced homogeneous sublots in Scenario 6 with the production lot with distribution $\beta_{k s}=0.4$ $0.3-0.3$. These scenarios attempt to assess the influence of LHP on the process of reallocating available quantities to committed orders.

\subsection{Assessing the results}

For each scenario, we analyse the maximum deliveries allowed in deliveries $\left(\max d_{o}\right)$, the number of order lines accepted and rejected, and the economic results comprised of the total rejecting costs, total margin and total profit obtained. Table 7 offers the results obtained after running the simulations which correspond to the first, second and third 
scenarios. We designed this set of scenarios to assess the effect of flexibility on the deliveries of orders.

Table 7. Results of scenarios with flexibility in deliveries

\begin{tabular}{|c|c|c|c|}
\hline Variable & Scenario 1 & Scenario 2 & Scenario 3 \\
\hline maxd $_{o}$ & 2 periods of time & 0 periods of time & unlimited \\
\hline$A O L$ & 316 & 287 & 326 \\
\hline$R O L$ & 34 & 63 & 24 \\
\hline$R C$ & $€ 149.600$ & $€ 189.974$ & $€ 116.051$ \\
\hline$\sum_{t} W M$ & $€ 337.468$ & $€ 283.573$ & $€ 382.138$ \\
\hline$P$ & $€ 187.900$ & $€ 93.599$ & $€ 266.087$ \\
\hline $\begin{array}{l}\text { AOL: order lines accepted; ROL: order lines rejected; RC: rejecting cost; } \sum_{t} W M: \text { total margin; } \\
\text { P: total profit obtained. }\end{array}$
\end{tabular}

These results revealed that the greater the flexibility allowed in order deliveries, the better the obtained results. Scenario 1 allowed a maximum delay of two periods of time per order. Here the profit made duplicated the results obtained by Scenario 2, which allowed no delays. Moreover, the delay allowed in Scenario 1 enabled us to serve 29 more order lines than when not permitting delays. From the results obtained in Scenario 3, which set no limit to the time in which to make deliveries, we served even more order lines (39 more than in Scenario 1). Therefore, we conclude that the results considerably improve by allowing flexibility when delivering orders.

Table 8 presents the results obtained for the scenarios that assessed system performance when making changes to the homogeneous sublots obtained with each production lot.

Table 8 . Results of the scenarios with homogeneity in distribution

\begin{tabular}{|c|r|r|r|r|}
\hline Variable & \multicolumn{1}{|c|}{ Scenario 1 } & \multicolumn{1}{c|}{ Scenario 4 } & \multicolumn{1}{c|}{ Scenario 5 } & \multicolumn{1}{c|}{ Scenario 6 } \\
\hline$\beta_{k s}$ & $0.7-0.2-0.1$ & $1.0-0.0-0.0$ & $0.5-0.5-0.0$ & $0.4-0.3-0.3$ \\
\hline$A O L$ & 316 & 328 & 322 & 310 \\
\hline$R O L$ & 34 & 22 & 28 & 40 \\
\hline$R C$ & $€ 149.571$ & $€ 127.544$ & $€ 137.185$ & $€ 168.613$ \\
\hline$\sum_{t} W M$ & $€ 337.468$ & $€ 366.813$ & $€ 353.959$ & $€ 312.055$ \\
\hline$P$ & $€ 187.873$ & $€ 239.269$ & $€ 216.774$ & $€ 143.442$ \\
\hline \multicolumn{2}{|l|}{$\begin{array}{l}\text { AOL: order lines accepted; ROL: order lines rejected; RC: rejecting cost; } \sum_{t} W M: \text { total margin; P: total } \\
\text { profit obtained. }\end{array}$} & & & \\
\hline
\end{tabular}

From the obtained results, we conclude that we can serve more order lines when homogeneous sublots include a bigger lot fraction. This positively affected the profits made as we rejected fewer orders, and we obtained a higher margin for the served products. Additionally, readers are referred to the following url in order to open through Vensim ${ }^{\circledR}$ the simulation model as a published version at: 


\section{Conclusions}

This article has presented a system dynamics model for the SP process in the ceramic sector based on the reallocation of stocked and planned available quantities to previously committed orders. This model has considered partial deliveries of order lines and the customer's requirement of homogeneity among units that comprise an order line, what makes the task of serving orders even more difficult. Additionally, a mathematical programming model with the same purpose has been proposed and used to validate the systems dynamics model. The comparison between the two models shows the better performance of the systems dynamics model as the number of orders increases with near optimal solutions in a very short time.

Once the system dynamics model validation has been proved, different what-if scenarios have been simulated to assess the system's real performance to such scenario. For that, the number of order lines accepted/rejected and economic results were analysed. Firstly, a new policy for the reallocation process based on serving the orders with the older available quantity that meet the customer's requirements was defined. This policy has been used for all the following scenarios. Secondly, we compare the system's performance when changing the maximum delay allowed per order. Here, we found that more orders can be served when the flexibility in deliveries increases. Finally, we generated three scenarios to verify the system's performance in light of different distributions of a production lot into different homogeneous sublots. From this set of scenarios, we conclude that it is easier to serve orders with homogeneous product when few sublots are obtained from a production lot. Therefore, the fewer the sublots obtained from a lot, the better the achieved results.

In literature, system dynamics models mainly focus on strategic problems (Tako and Robinson, 2011; Jeon and Kim, 2016). However, the computational efficiency of the proposed system dynamics model proves that it is also an excellent operational tool to reallocate available products to committed orders. Managerial implications focus on integrating the system dynamics model into the information system of companies. Moreover, it is possible to use the tool to do what-if analyses according to managers' requirements. Specific system dynamics formation for managers would be desirable to obtain more flexible and robust simulation models.

Some future improvements for the current proposal have been detected. In this work, we particularly managed to adjust the SP process in a way that real and planned available quantities of product were reallocated to previously committed orders. This process is held at the start of the simulation so that it is decided if the produced units are going to be stocked, reserved to serve a committed order until its due date, or directly served to customers. In future works, different inventory reallocation policies could be employed; e.g. instead of serving an order with the oldest homogeneous sublot, we could serve it with the smaller homogeneous sublot that meets the order requirements. This would decrease the number of small homogeneous sublots available at the company and would increase the probability to serve big amounts of product with homogeneous product. Furthermore, the simulation could consider orders of different sizes. It would better 
represent reality as each order can be comprised by a different number of order lines. Similarly, it would be possible to consider that the same product can be demanded in more than one line of the same order. Finally, the system dynamic model could be extended by assuming that two or more lines of the same order need to be homogeneous. This would be very valuable by ceramic industries in which it is necessary to ensure that products that are going to be assembled together display homogeneity with each other.

\section{Bibliography}

Alarcón, F., Alemany, M.M.E., Lario, F., Oltra, R. (2011). La Falta de Homogeneidad del Producto (FHP) en las Empresas Cerámicas y su Impacto en la Reasignación de Inventario. Boletín de la Sociedad Española de Cerámica y Vidrio 50 (1): 49-58. doi:10.3989/cyv.072011

Alemany, M.M.E., Alarcón, F., Oltra, R., Lario, F. (2013a). Reasignación Óptima del Inventario a Pedidos en Empresas Cerámicas Caracterizadas por la Falta de Homogeneidad en el Producto (FHP). Boletín de la Sociedad Española de Cerámica y Vidrio 52 (1): 31-41. doi:10.3989/cyv.42013

Alemany, M.M.E., Lario, F., Ortiz, A., Gómez, F. (2013b). Available-To-Promise Modeling for Multi-Plant Manufacturing Characterized by Lack of Homogeneity in the Product: An Illustration of a Ceramic Case. Applied Mathematical Modelling 37 (5): 3380-3398. doi:10.1016/j.apm.2012.07.022

Alemany MME, Ortiz A, Boza A, Fuertes-Miquel VS (2015a) A model-driven decision support system for reallocation of supply to orders under uncertainty in ceramic companies. Technol Econ Dev Econ 21(4):596-625

Alemany, M.M.E., Grillo, H., Ortiz, A., Fuertes-Miquel, V. S. (2015b). A Fuzzy Model for Shortage Planning under Uncertainty due to Lack of Homogeneity in Planned Production Lots. Applied Mathematical Modelling 39 (15): 4463-4481. doi:10.1016/j.apm.2014.12.057

Boza, A., Alemany, M.M.E., Alarcón, F., Cuenca, L., (2014). A Model-Driven DSS Architecture for Delivery Management in Collaborative Supply Chains with Lack of Homogeneity in Products. Production Planning \& Control 25 (8): 650-661. doi:10.1080/09537287.2013.798085

Campuzano, F., Mula, J. (2011). Supply Chain Simulation: A System Dynamics Approach for Improving Performance. Ed. Springer-Verlag London.

Campuzano-Bolarin, F., Mula, J., Peidro, D. (2013). An Extension to Fuzzy Estimations and System Dynamics for Improving Supply Chains. International Journal of Production Research 51 (10): 3156-3166. doi:10.1080/00207543.2012.760854

Forrester JW. 1961. Industrial Dynamics. The MIT Press. Massachusetts Institute of Technology, Cambridge, Massachusetts.

Framinan, J.M., Leisten, R. (2010). Available-To-Promise (ATP) Systems: A Classification and Framework for Analysis. International Journal of Production Research 48: 3079-3103. doi:10.1080/00207540902810544

Georgiadis, P., Michaloudis, C. (2012). Real-Time Production Planning and Control System for Job-Shop Manufacturing: A System Dynamics Analysis. European Journal of Operational Research 216 (1): 94-104. doi:10.1016/j.ejor.2011.07.022

Georgiadis, P., Politou, A, (2013). Dynamic Drum-Buffer-Rope Approach for Production Planning and Control in Capacitated Flow-Shop Manufacturing Systems. Computers \& Industrial Engineering 65 (4): 689-703. doi:10.1016/j.cie.2013.04.013 
Grillo, H., Alemany, M.M.E., Ortiz, A. (2016) A Review of Mathematical Models for Supporting the Order Promising Process Under Lack of Homogeneity in Product and Other Sources of Uncertainty. Computers \& Industrial Engineering 91: 239-261.

Grillo, H., Alemany, M.M.E., Ortiz, A., Mula, J. (2017). A Fuzzy Order Promising Model with Non-Uniform Finished Goods. International Journal of Fuzzy Systems. In press. doi:10.1007/s40815-017-0317-y

Jeon, S.M., Kim, G. (2016). A Survey of Simulation Modeling Techniques in Production Planning and Control (PPC). Production Planning and Control 27 (5): 360-377. doi:10.1080/09537287.2015.1128010

Mula, J., Campuzano, F., Díaz-Madroñero, Karpio, K.M. (2013). A System Dynamics Model for the Supply Chain Procurement Transport Problem: Comparing Spreadsheets, Fuzzy Programming and Simulation Approaches. International Journal of Production Research 51 (13): 4087-4104. doi:10.1080/00207543.2013.774487

Olhager, J. (2003). Strategic Positioning of the Order Penetration Point. International Journal of Production Economics, 85(3), 319-329. doi: 10.1016/S0925-5273(03)00119-1

Sterman, J.D. (2000). Business Dynamics: Systems Thinking and Modeling for a Complex World. McGraw-Hill, Boston.

Tako, A., Robinson, S. (2011). The Application of Discrete Event Simulation and System Dynamics in the Logistics and Supply Chain Context. Decision Support Systems 52 (4): 802-815. doi:10.1016/j.dss.2011.11.015 